\title{
Cost-effectiveness of early intervention in psychosis: systematic review
}

\author{
David Aceituno, Norha Vera, A. Matthew Prina and Paul Mccrone
}

\section{Background}

Early intervention in psychosis (EIP) has been developed as an approach to improve the prognosis of people with psychotic disorders and it has been claimed to be a more efficient model of care. However, the evidence is not definitive and doubts have spread regard to the economic outcomes of EIP services amid the usually restricted mental health budget.

\section{Aims}

We aimed to review the cost-effectiveness evidence of EIP services worldwide.

\section{Method}

We systematically reviewed the economic literature about EIP following the Preferred Reporting Items for Systematic reviews and Meta-Analyses statement guidelines. Studies were selected according to previously stated criteria and analysed with standardised critical appraisal tools for trial-based economic evaluations and modelling studies.

\section{Results}

A total of 16 studies were selected after applying the eligibility criteria. Most of them were economic evaluations alongside clinical trials. The overall evidence was consistent in the costeffectiveness of EIP compared with standard care for first episode of psychosis and the Clinical High Risk for Psychosis paradigm. Such evidence was replicated among different health systems, but mainly in high-income countries. The methodological quality of such evidence, however, was moderate and heterogeneity was significant across the studies.

\section{Conclusions}

There is consistent evidence that the implementation of EIP services might be a cost-effective alternative across different health systems. Such evidence, nevertheless, derives from heterogeneous and sometimes methodologically flawed studies, reducing the certainty of such statement. More efforts must be done to rigorously assess the value of this intervention, before expanding it among systems where mental health budgets are more constrained.

\section{Declaration of interest}

None.

\section{Keywords}

Schizophrenia; cost-effectiveness; psychotic disorders.

\section{Copyright and usage}

(c) The Royal College of Psychiatrists 2019.
David Aceituno (pictured) is a clinical psychiatrist from Chile, where he used to work in a day hospital for people with psychotic and personality disorders in a deprived area of Santiago. After that, he completed a MSc in Global Mental Health, a joint programme between London School of Hygiene and Tropical Medicine and King's College London. Currently, he is a PhD candidate in Health Economics at King's College London, investgating the cost-effectiveness of early intervention in psychosis services in Latin America. Norha Vera completed undergraduate training in psychology at the Complutense University and the Autonomous University of Madrid, as well as an MSc in Psychiatric Research at the IOPPN. She is interested in the development of culturally appropriate mental health services in low and middle-income countries, the role of informal carers, and the effect of social factors on mental health and treatment effectiveness. Her PhD research consists in identifying cultural dimensions associated with recovery and wellbeing in Latin America, to then adapt a measure of recovery for use in the region.

A. Matthew Prina is a senior lecturer in epidemiology in the Institute of Psychiatry, Psychology and Neuroscience at King's College London and Head of the Social Epidemiology Research Group. He initially studied at the University of Glasgow, and then moved to Cambridge University to complete an MPhil in Epidemiology and a PhD in Public Health. He became an MRC Population Health Scientist Research Fellow within the Centre for Global Mental Health at King's College London in 2013, before being appointe Lecturer in Ageing and Mental Health. Matthew has co-led many seminal reports on ageing, specifically around dementia care, risk factors, numbers and estimates, published by Alzheimer's Disease International, Alzheimer's Society and the World Health Organisation. Paul Mccrone is Professor of Health Economics and Director of KHE, having worked at the Institute of Psychiatry, Psychology and Neuroscience for 25 years after previously working at the University of Kent. Paul studied Political Economy at Thames Polytechnic and Economics at Birkbeck College. He has worked on a large number of economic studies in health and social care. Currently he is involved in evaluations in psychiatry, neurology and palliative care. He also teaches health economics to Masters-level students, supervises PhD students, and has published widely in peer reviewed journals. Recently Paul became co-director of the Mental Health Policy Research Unit funded by NIHR.

\section{EIP: a change in psychosis care}

There is substantial worldwide evidence of the social effect of psychosis. Having a psychotic disorder is associated with a myriad of social determinants, such as poverty, unemployment, income inequality, immigration, incarceration and homelessness, among others. ${ }^{1}$ Recent evidence suggests that some of these factors might have a causal role in the onset of psychosis, resulting in a vicious circle between social disadvantage and mental illness. ${ }^{2,3}$ Furthermore, some studies have shown a clear gap in treatment access for people with psychosis, in both high- and low- and middle-income countries. ${ }^{4}$

This situation seemed to change in the early 1990s with a service transformation intended to improve the care of people with psychosis by explicitly intervening in the early stages of the illness. ${ }^{5}$ The early intervention in psychosis (EIP) movement gained academic and political support and is now probably one of the most disseminated models of care among high-income countries, with several less-resourced regions also starting similar programmes. ${ }^{6-9}$

Nevertheless, such implementation has been far from uncontroversial, with much discussion regarding the evidence base for this approach. Proponents and detractors have generated a considerable amount of research and comments on the topic, challenging the supposed consensus reached at the beginning of the century. ${ }^{10}$

\section{EIP: the economic case}

One aspect that has been subject of attention from the beginning of EIP service implementation is the economic implications of the approach. For instance, despite initial positive results of economic evaluations, ${ }^{11}$ in 2012 a systematic review concluded that 'the published literature does not support the contention that EIP reduces costs or achieves cost-effectiveness' ${ }^{12}$

Nevertheless, the conclusions of this review should be taken with caution, given that the author based some of his arguments on differences in the case-loads between EIP services and 'generic' mental health teams, as well as on the financial costs attributable 
to hospitalisation. However, cost-effectiveness studies use unit costs in the analysis and its focus is on the opportunity cost more than the financial cost. Thus, a new technology might be more expensive and still be cost-effective. ${ }^{13}$

Furthermore, given the uncertainty associated with any decision, the question about cost-effectiveness is not a black-orwhite alternative, but a probabilistic one. ${ }^{13}$. Therefore, a thorough economic evaluation should include methods to handle decision uncertainty, such as sensitivity analyses or simulation methods (e.g. bootstrapping and cost-effectiveness acceptability curves; CEACs). ${ }^{13,14}$ Finally, judgement about the cost-effectiveness of any health technology relies heavily on the characteristics of the health system, and so conclusions should always be contextualised.

Since the last review, new economic evaluations have been published from different countries, and so we aim to systematically review the international evidence on cost-effectiveness of EIP services.

\section{Method}

A systematic review of the literature, following the Preferred Reporting Items for Systematic reviews and Meta-Analyses (PRISMA) guidelines, ${ }^{15}$ was conducted to identify economic evaluations of EIP services. A protocol was developed before searching electronic databases and was registered on PROSPERO (identifier CRD42017080796).

\section{Eligibility criteria}

Inclusion and exclusion criteria are outlined in Table 1. Briefly, the review included all the studies that analyse EIP against an alternative approach and that report costs and outcomes, regardless of the particular type of economic evaluation (trial-based or modelling). No limits were applied to language and publication date.

\section{Electronic searches}

An electronic search was done in the following databases: the Cochrane library, Medline, PsycInfo, EMBASE, EconLit and National Health Service Economic Evaluation Database (NHS EED) of University of York. The search strategy included terms such as 'psychosis' or 'ultra-high risk' and 'cost-analysis' or 'economic evaluation'.

A complete search strategy list is provided in the Supplementary material available at https://doi.org/10.1192/bjp.2018.298. Furthermore, the search also included cross-referencing and conferences proceedings from the International Early Psychosis Association. Finally, authors were contacted for incomplete data or doubts regarding the publication.

\section{Study selection}

Two authors (D.A. and N.V.) independently screened titles and abstracts from unduplicated references according to eligibility criteria. When a decision was not possible from reading the abstract, the full text was reviewed and again contrasted with inclusion and exclusion criteria. Disagreements were resolved by discussion with a third author (P.M.).

\section{Data collection and risk of bias assessment}

Data were collected using an extraction form developed to retrieve relevant information. This included general information of the study and key methodological characteristics (study design, setting, type of economic evaluation, perspective, analytical approach, time horizon, discounting, source of data for costs and

\begin{tabular}{|c|c|}
\hline Inclusion & Exclusion \\
\hline $\begin{array}{l}\text { Population: FEP (affective and non- } \\
\text { affective) and at CHR-P of } \\
\text { psychosis, regardless of age, } \\
\text { gender and ethnicity. }\end{array}$ & $\begin{array}{l}\text { Studies with samples in which more } \\
\text { than } 30 \% \text { of participants had a } \\
\text { chronic psychotic disorder. }\end{array}$ \\
\hline $\begin{array}{l}\text { Intervention: early detection and } \\
\text { specialised care for people with } \\
\text { FEP delivered by }\end{array}$ & $\begin{array}{l}\text { Studies analysing interventions in } \\
\text { isolation (e.g. pharmacotherapy, } \\
\text { cognitive-behavioural therapy) }\end{array}$ \\
\hline $\begin{array}{l}\text { multidisciplinary teams, } \\
\text { according to international } \\
\text { guidelines. }^{10}\end{array}$ & No comparator described. \\
\hline $\begin{array}{l}\text { Comparator: standard mental } \\
\text { healthcare, without any phase- } \\
\text { specific treatment or specialised } \\
\text { team. }\end{array}$ & $\begin{array}{l}\text { Studies reporting only outcomes } \\
\text { without costs. }\end{array}$ \\
\hline $\begin{array}{l}\text { Outcomes: any measurement of } \\
\text { cost-effectiveness or cost-utility } \\
\text { analysis. }\end{array}$ & $\begin{array}{l}\text { Partial economic evaluation (e.g. } \\
\text { cost analysis, cost- } \\
\text { minimisation). }\end{array}$ \\
\hline $\begin{array}{l}\text { Study design: trial-based and model- } \\
\text { based completed economic } \\
\text { evaluations. }\end{array}$ & $\begin{array}{l}\text { Budget impact and cost-of-illness } \\
\text { studies. } \\
\text { Methodological studies. }\end{array}$ \\
\hline
\end{tabular}

effects, outcome measures, cost data, year of costing and results with uncertainty analysis).

The methodological quality of the economic evaluations conducted alongside clinical trials was assessed by the Consensus Health Economic Criteria (CHEC) list ${ }^{16}$ and the Cochrane Risk of Bias tool. ${ }^{17}$ In the case of model-based studies, the questionnaire designed by the International Society for Pharmacoeconomics and Outcomes Research, Academy of Managed Care Pharmacy and National Pharmaceutical Council (ISPOR-AMPC-NPC) Good Practice Task Force was chosen to evaluate methodological quality of included models. ${ }^{18}$

\section{Synthesis of results}

Studies were not pooled for two reasons: (a) evident heterogeneity in the characteristics in terms of different countries, populations and methodologies to measure costs and outcomes; and (b) because a pooled estimate is difficult to interpret given the importance of local context in health technology assessment. ${ }^{19}$ Therefore, a narrative synthesis of key results for first-episode psychosis (FEP) and Clinical High Risk for Psychosis (CHR-P) ${ }^{20}$ populations is presented.

\section{Results}

\section{Study selection}

A total of 6860 unduplicated studies were retrieved from the database search, hand-searched and cross-referenced. After reading titles and abstracts, 33 full texts were analysed and inclusion and exclusion criteria applied. From these, seven were excluded because they were incomplete economic evaluations (cost analysis and cost-minimisation analysis), six were discarded because they were not addressing the research question and four were discarded because the focus was on financing models of EIP services. The remaining 16 studies were included in the qualitative analysis of the review. A flow diagram of this process, according to PRISMA guidelines is presented in Fig. 1.

\section{Study characteristics}

The main characteristics of the included studies are listed in Table 2. Most of the studies $(n=14)$ were trial-based economic evaluations, 


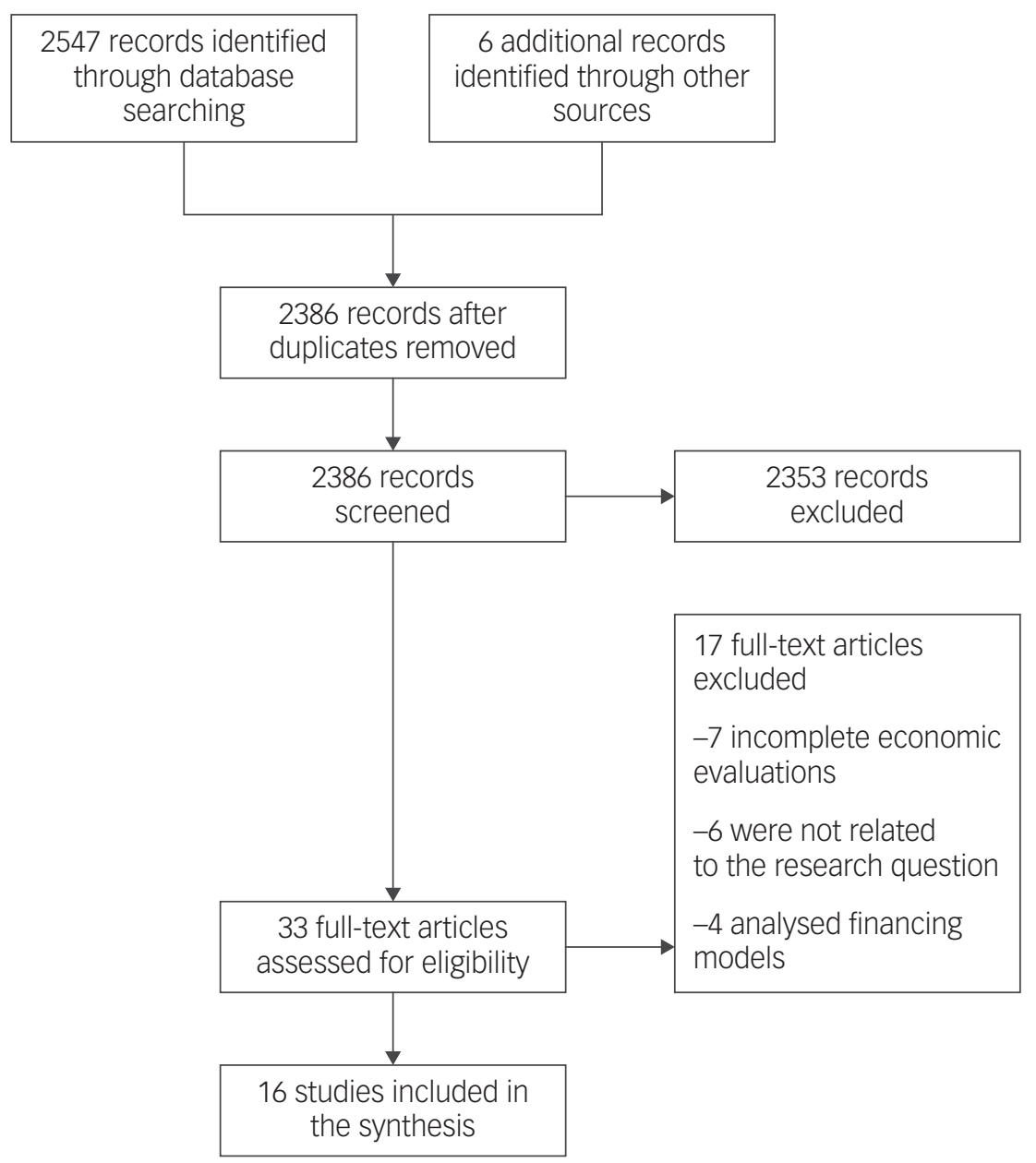

Fig. 1 Preferred Reporting Items for Systematic reviews and Meta-Analyses flowchart.

assessing the cost-effectiveness of EIP services compared with standard care. A minority of studies $(n=4)$ also included a cost-utility analysis, reporting quality-adjusted life-years (QALYs) as a measure of outcome. Six of the economic evaluations were based on randomised controlled trials (RCT), whereas the rest used non-RCT designs, such as pre-post designs and matched case-control designs.

All the studies adopted a healthcare system perspective in the analysis, but almost half (44\%) also included a broader perspective, mainly by adding productivity losses. A few studies included costs falling for social care ${ }^{21-23}$ and the criminal system. ${ }^{24}$

\section{Results of individual studies}

\section{Early intervention for FEP}

A total of 12 studies from 11 trials $(n=6597)$ reported an economic evaluation of EIP services, comparing them with standard care ${ }^{22,24-27}$ or with a historical control group. ${ }^{11,28-31}$ Furthermore, one model-based study was identified. ${ }^{32}$ Although a previous modelling study has been published, ${ }^{33}$ this was excluded because it adopted a cost-minimisation approach.

In general, EIP services were very similar between studies, consisting of specialised multidisciplinary teams in a catchment area, and offering low doses of medication and psychosocial interventions. Psychosocial interventions included cognitive-behavioural therapy for psychosis, family therapy and vocational rehabilitation. Furthermore, some programmes ${ }^{11,21,22,24}$ were explicit in their adherence to assertive community treatment principles to safeguard continuity of care.
Participants were aged between 14 and 65 years and all the studies except on $e^{25}$ included affective psychotic disorders in their samples. The outcomes were highly heterogeneous among the studies, including measures of symptoms, social functioning, suicide attempts, substance misuse, employment, housing status and quality of life.

Information regarding service utilisation was available in 7 out of 16 studies. Authors measured this variable using different methodologies and at different follow-up points. However, a certain pattern of resource use was observable, in which EIP services were mostly associated with a reduction in in-patient utilisation (e.g. days in hospital), but with increased contacts with psychiatrists, psychologists and nurses.

Cost estimates from all but two studies were lower in the EIP group. However, only half of the studies reported a measure of precision, which limits the analysis of cost uncertainty. The presentation of cost results was dissimilar between the studies, showing total costs of the programme, cost per patient, monthly costs and costs at various follow-up periods.

Table 3 shows a summary of the cost-effectiveness results and methods to deal with uncertainty of estimates. Most of the studies $(n=8)$ included an incremental analysis of costs and outcomes, and 9 out of 12 used methods to handle the uncertainty of estimates. Cocchi et $a l^{27}$ and Zhang et $a l^{25}$ presented an incremental costeffectiveness ratio (ICER) as a measure of cost-effectiveness. In the former, the EIP service achieved a net saving of $€ 1204$ per unit reduction on the Health of the Nation Outcome Scale. ${ }^{27}$ In the latter, the intervention resulted in an ICER of US\$1819.4 per QALY gained. ${ }^{25}$ 


\begin{tabular}{|c|c|c|c|c|c|c|}
\hline Study & Year & Country & Study design & $N$ & Perspective $^{a}$ & Time horizon (years) \\
\hline \multicolumn{7}{|c|}{ Trial-based economic evaluations } \\
\hline Mihalopoulos et a $/^{11}$ & 1999 & Australia & Non-RCT (historical matched control) & 102 & Healthcare system & 1 \\
\hline Cullberg et $a^{28}$ & 2006 & Sweden & Non-RCT (matched control) & 86 & Healthcare system & 3 \\
\hline Goldberg et $a^{29}$ & 2006 & Canada & Non-RCT (historical control) & 305 & Healthcare system & 2 \\
\hline Mihalopoulos et $a^{30}$ & 2009 & Australia & Non-RCT (historical matched control) & 65 & Healthcare system & 6 \\
\hline McCrone et $a^{24}$ & 2010 & UK & $\mathrm{RCT}$ & 136 & Societal & 1.5 \\
\hline Cocchi et al ${ }^{27}$ & 2011 & Italy & Non-RCT (matched control) & 46 & Healthcare system & 5 \\
\hline Wong et $a l^{34}$ & 2011 & China & Non-RCT (historical control) & 130 & Healthcare system & 2 \\
\hline Hastrup et $a^{22}$ & 2013 & Denmark & $\mathrm{RCT}$ & 301 & Societal & 5 \\
\hline Zhang et $a^{25}$ & 2014 & China & $\mathrm{RCT}$ & 1184 & Societal & 1 \\
\hline Behan et $a l^{31}$ & 2015 & Ireland & Non-RCT (historical control) & 229 & Healthcare system & NA \\
\hline Ising et $\left.a\right|^{35}$ & 2015 & Netherlands & $\mathrm{RCT}$ & 196 & Societal & 1.5 \\
\hline Rosenheck et al ${ }^{26}$ & 2016 & USA & Cluster RCT & 404 & Healthcare system & 2 \\
\hline Tsiachristas et $\left.a\right|^{21}$ & 2016 & UK & Retrospective observational study & 3674 & Societal & 3 \\
\hline Ising et $\left.a\right|^{36}$ & 2017 & Netherlands & $\mathrm{RCT}$ & 113 & Societal & 4 \\
\hline \multicolumn{7}{|c|}{ Model-based economic evaluations } \\
\hline Perez et $a l^{23}$ & 2015 & UK & $\mathrm{N} / \mathrm{A}$ & $\mathrm{N} / \mathrm{A}$ & Healthcare system & 2 \\
\hline Park et $a /^{32}$ & 2016 & UK & $N / A$ & $\mathrm{~N} / \mathrm{A}$ & Societal & $2,4,10$ \\
\hline
\end{tabular}

Mihalopoulos $e \mathrm{al}^{11}$ considered the Early Psychosis Prevention \& Intervention Centre (EPPIC) to be 'dominant' (i.e. cost-saving and outcome-improving) over the 'pre-EPPIC' group, and so an incremental analysis was not necessary. Nevertheless, in the longterm follow-up, a bootstrapping analysis with 1000 iterations was performed, resulting in almost $100 \%$ of the iterations from the EPPIC group remaining the less costly alternative.

McCrone et $a l^{24}$ used the net-benefit approach to derive CEACs at different values of willingness-to-pay (WTP) for a unit improvement in outcome. In this study, EIP services had a $76 \%$ probability of being the most cost-effective alternative if the society is willing to pay $£ 0$ per vocational recovery. This likelihood was $92 \%$ when the outcome considered was a unit improvement in a quality-of-life score, at the same zero WTP. ${ }^{24}$

Finally, Wong et $a l^{34}$ Hastrup et $a l^{22}$ and Rosenheck et al ${ }^{26}$ presented ICERs, cost-effectiveness planes and CEACs to describe cost-effectiveness. The authors were consistent in showing results favourable to EIP. It is also noteworthy that in the case of the Recovery After an Initial Schizophrenia Episode study, the net-benefit analysis showed a $94 \%$ likelihood of EIP being the most cost-effective option at US $\$ 40000$ per standard-unit increment in the quality-of-life scale. ${ }^{26}$ When the analysis was performed considering QALY, the probability of being cost-effective remained high (90\%), but at a WTP of US\$210 000 per QALY, which is higher the cost-effectiveness threshold of many countries. ${ }^{26}$
In all of the studies that used one-way sensitivity analyses, the results were robust to changes made by the authors. However, parameters selected were heterogeneous and rather arbitrary. For instance, Mihalopoulos et $\mathrm{al}^{11}$ changed the cost of the programme by $50 \%$, whereas Zhang et $a l^{25}$ changed the clinical effects and costs by $\pm 20 \%$ and Wong et $a l^{34}$ used a $15 \%$ difference in costs. Rosenheck et $a l^{26}$ conducted a subgroup analysis based on the duration of untreated psychosis (DUP). This revealed an ICER of US\$7245 per QALY among low-DUP participants and US\$289 149 per QALY among high-DUP participants. ${ }^{26}$ Finally, Tsiachristas et al performed scenario analyses where EIP services remained as cost-saving alternatives, changing from a conservative scenario of $£ 36.6$ million annually to an optimistic scenario of $£ 68$ million per year. ${ }^{21}$

\section{Early intervention for the CHR-P population}

Two publications from a single trial were included in the review. ${ }^{35,36}$ Although a previous economic evaluation based on an RCT had been published, this was excluded because it adopted a costminimisation analysis. ${ }^{37}$

The included trial was a cluster RCT of 196 people with CHR-P, comparing the addition of cognitive-behavioural therapy to routine care against routine care alone in four treatment centres in the Netherlands. The primary and secondary outcomes were transition to psychosis and health-related quality of life, respectively. As a

\begin{tabular}{|c|c|c|c|c|}
\hline Study & Currency & Outcome & Cost-effectiveness & Uncertainty analysis \\
\hline Mihalopoulos et a/ ${ }^{11}$ & Australian dollar & Quality of life & ICER -AUS\$456 per improvement in quality of life score & DSA \\
\hline Cullberg et $a l^{28}$ & Swedish krone & GAF & ICER -SEK7410 per improvement in GAF score & Not performed \\
\hline Goldberg et $a^{29}$ & Canadian dollar & Hospital admissions & ICER -CAN\$26718 per reduction in admissions & Not performed \\
\hline Mihalopoulos et $a^{\beta 0}$ & Australian dollar & BPRS & $100 \%$ likelihood of EIP being more cost-effective at AUS\$0 WTP & DSA, PSA \\
\hline Mccrone et $a l^{24}$ & Pound sterling & Quality of life & 92\% likelihood of EIP being more cost-effective at £0 WTP & PSA \\
\hline Cocchi et $a 2^{27}$ & Euro & HoNOS total score & ICER -€1204 per incremental score reduction & DSA \\
\hline Wong et $a \beta^{34}$ & Hong Kong dollar & Psychiatric admissions & 94.4\% likelihood of EIP being more cost-effective at HK\$O WTP & DSA, PSA \\
\hline Hastrup et $a l^{22}$ & Euro & GAF & 96.5\% likelihood of EIP being more cost-effective at €2000 WTP & DSA, PSA \\
\hline Zhang et $a^{25}$ & US dollar & QALYS & ICER US\$1819.4 per QALY gained & DSA \\
\hline Behan et $a l^{\beta 1}$ & Euro & Length of stay (days) & ICER -€279.3 per reduction in days spent in hospital & Not performed \\
\hline Rosenheck et al ${ }^{26}$ & US dollar & Quality of life and QALYS & 95\% likelihood of EIP being more cost-effective US\$40 000 WTP & DSA, PSA \\
\hline Tsiachristas et $a l^{21}$ & Pound sterling & Employment & Mean $£ 4031$ cost-saving associated with EIP & DSA, PSA \\
\hline
\end{tabular}


result, a cost-effectiveness and a cost-utility analysis were performed. The results at 1.5-year follow-up showed that the intervention led to a statistically significant difference in transition to psychosis (risk difference, $0.133 ; P=0.004$ ) and a non-significant difference of 0.03 QALYs.

The incremental analysis demonstrated that the intervention was also cost-saving (by US\$844). Uncertainty analyses revealed that there was a $63.7 \%$ likelihood of lower costs and lower transition to psychosis as a result of the intervention. Similar analyses revealed a $52.3 \%$ likelihood of lower costs and more QALYs. ${ }^{35}$

The 4-year follow-up, ${ }^{36}$ using data from 113 patients (43.3\% of attrition), continued to show reduced transition to psychosis (risk difference, 0.122; $P<0.001$ ) and more QALYs (difference, 0.164; $P=0.28)$ in the intervention group. The economic evaluation thus continued favouring the intervention over the long term, with results being robust to different sensitivity analyses.

A decision-analytic model that analysed the cost-effectiveness of different interventions to detect and refer people with CHR-P from primary healthcare to EIP services was also included in the review. The results showed that the high-intensity intervention was associated with better outcomes (CHR-P cases, correctly identified and referred) and lower costs. The CEAC demonstrated that the high-intensity intervention had a $68 \%$ likelihood of being the most cost-effective option at a WTP of $£ 10000$ per correctly identified case of CHR-P. This likelihood increases to $77 \%$ when the WTP rises to $£ 20000 .^{23}$

\section{Risk of bias within and across the studies}

The risk of bias of the included clinical trials, according to the Cochrane risk of bias tool, ${ }^{17}$ was rather mixed. Most of the unmet criteria were those related with selection bias and blinding, primary because of the study design of some trials. Although none of the studies blinded the participants, this was understandable, given the nature of the interventions. However, investigator and analyst masking was unclear by more than half of the studies. Regarding the methodological quality of the economic evaluations, the results of the CHEC checklist show that nearly $60 \%$ of the studies met most of the quality criteria ( $\geq 16$ out of 19 ), although $21 \%$ of the studies did not meet half of the quality criteria. One of the main limitations was the perspective selected, where only $43.7 \%$ of the studies included data outside the healthcare system. Likewise, incremental analyses and discounting were applied by about half of the studies.

The two model-based studies included in this systematic review were conducted in the UK and were built in a formal and transparent way, using published data and expert opinion. Uncertainty was addressed and the assumptions made seem plausible, considering the natural history of the disease, as well as the evidence about EIP services. In the case of Perez et $a l^{23}$, however, the assumption about the costs of treatment-as-usual should be revised, given that is unlikely to be zero. Likewise, the structural assumptions required for decision-tree models can be a limitation because they do not easily allow long-term effects to be addressed, particularly with psychotic conditions with a high likelihood of relapse. Despite these caveats, the modelling studies included represent good-quality and valuable information to help assess the cost-effectiveness of EIP programmes.

For a more comprehensive picture, a detailed list of the risk of bias tool and the CHEC checklist is provided in Supplementary material D1 and D2, respectively.

\section{Discussion}

The present systematic review has shown that EIP might be a costeffective technology to implement into mental health systems, compared with standard of care. Investing in EIP could, as the best-case scenario, save money, and is at least a more cost-effective alternative than treatment as usual.

These results are consistent among different health systems and they have been replicated alongside clinical trials, as well as in model-based economic evaluations. Regardless of this consistency in the evidence, some caveats should be acknowledged. First, the certainty of such evidence is moderate because the risk of bias in some studies is high, and more rigorous trials have failed to demonstrate clinical or functional differences with standard care, diminishing the size of clinical and economic advantages.

Second, the methodological quality of economic evaluations was mixed, with some studies incorporating most of the rigorous methods recommended, and others showing just direct results that were impossible to track from the reported methodology. Whether this is a methodological or reporting problem is difficult to say. Authors were contacted to complete data, but it was not possible to get access to all of the information.

Third, most of the economic evaluations in this review have not included the whole picture of the economic effect of psychosis. For instance, none of the studies measured out-of-the-pocket expenses or carer costs, which have been recognised as a significant problem in cost-of-illness studies. ${ }^{38}$ Likewise, only 5 out of 16 of the analysed studies included costs from a wide perspective, considering the effect of psychosis on the social care or the justice system.

Fourth, although all the studies used 'standard of care' or 'treatment as usual' as their control arm, the definition and details of such type of services were not always clearly stated, which makes comparisons between health systems problematic. In fact, the heterogeneity of studies impeded a meta-analysis of results.

Finally, it is important to acknowledge that many of the studies were conducted by advocates of EIP services. This does not necessarily mean that the results of the studies were influenced by vested interests, but it might add potential bias. It is known that the benefits of interventions might be overstated by proponents or developers, especially in the early phases of research. ${ }^{39}$

Notwithstanding these limitations, the results presented here are not concordant with those exposed by Amos in a previous systematic review. ${ }^{12}$ Although a critical analysis to this research is justified, given the methodological flaws already highlighted, the results show a consistent direction toward the economic benefits of EIP services.

\section{Implications for mental health policy}

From the perspective of the health systems, the results of this systematic review suggest that EIP has been an adequate policy. This is an important conclusion, considering the budget constraints and critics to EIP services since its implementation. ${ }^{40}$ It is still necessary, however, to elucidate which aspects of the EIP approach are more relevant. In other words, what are the 'active ingredients' (reducing DUP, multidisciplinary teams, an assertive community treatment approach or other) that explain better outcomes, to focus the policy and make it even more efficient and sustainable.

Nevertheless, these implications might change when low- and middle-income countries are considered. Most of the studies in this review have been conducted in high-income countries, and the applicability of this research to low- and middle-income countries should be taken with caution. This aspect is crucial, considering the academic and political success that EIP have gained in influential countries such as the UK, Scandinavia, Australia and USA. Indeed, probably based on such experiences, several EIP initiatives have been implemented in less-resourced settings. ${ }^{8,9}$ This opens a debate about whether health initiatives, although effective and 
even cost-effective, should be implemented in settings where more basic services are lacking. There is no straightforward answer for this, but a different approach may be needed, ${ }^{41}$ one in which the reality of mental health systems converges with good-quality evidence and people's needs.

\section{Implications for research}

Despite the considerable amount of research published on EIP, there is still room to improve the methodological rigour, to replicate findings in independent samples and monitor real-world implementation. Also, it is necessary to include measurements that people value more, such as social recovery, quality of life and carers' needs, and indicators relevant to health systems and policy makers, such as budget impact analyses and equity measurements. This systematic review has shown that these topics are starting to be incorporating in the EIP research agenda, but certainly there is a need of more and better-quality research.

\section{Strengths and limitations}

This review has several strengths. First, a comprehensive and reproducible search was performed. No restrictions were applied and the electronic search was complemented with hand-searching, crossreferencing and searching in conference publications of relevant societies. Furthermore, the use of PRISMA guidelines adds transparency, rigour and completeness to the research. Also, all the studies were subject to a quality assessment with consolidated tools. This reduces, although does not eliminate, the subjectivity in the critical appraisal of individual studies.

However, this systematic review has several limitations. For instance, despite the comprehensiveness of the searching, unpublished or local economic evaluations could be missed. Furthermore, given the high heterogeneity of the studies, a meta-analysis was not possible. Finally, as was discussed, this systematic review only included studies conducted in high-income countries, which reduces its generalisability to settings with fewer resources.

In conclusion, the evidence supports that investment in EIP services might be a cost-effective alternative for those countries where they have been implemented. The quality of the overall evidence is moderate, although consistent across different settings. However, the effect of EIP services on health disparities as well as the transferability of these results to low- and middle-income countries remains unknown. Thus, more research is needed to elucidate how and which aspects of EIP services could be adopted by mental health systems, to improve system efficiency and sustainability, and equally importantly, to increase the quality of life of people with psychotic disorders.

\footnotetext{
David Aceituno, MD DD, PhD Candidate, Health Service and Population Research
Department, Institute of Psychiatry, Psychology and Neuroscience, King's College London, UK; and Psychiatry Department, School of Medicine, Pontificia Universidad Católica de Chile, Chile; Norha Vera, MSC, PhD Candidate, Health Service and Population Research Department, Institute of Psychiatry, Psychology and Neuroscience, King's College London, UK; A. Matthew Prina, PhD, Senior Lecturer in Epidemiology, Health Service and Population Research Department, Institute of Psychiatry, Psychology and Neuroscience, King's College London, UK; Paul Mccrone, PhD, Professor of Heath Neuroscience, King's College London, UK; Paul Mccrone, PhD, Professor of Health
Economics, Health Service and Population Research Department, Institute of Psychiatry, Psychology and Neuroscience, King's College London, UK

Correspondence: David Aceituno, Health Service and Population Research Department, Institute of Psychiatry, Psychology \& Neuroscience, King's College London, De Crespigny Park, London, SE5 8AF, UK. Email: david.aceituno_farias@kcl.ac.uk

First received 29 May 2018, final revision 4 Oct 2018, accepted 17 Nov 2018
}

\section{Supplementary material}

Supplementary material is available online at https://doi.org/10.1192/bjp.2018.298

\section{References}

1 Morgan C, McKenzie K, Fearon P. Society and Psychosis. Cambridge University Press, 2008.

2 Radua J, Ramella-Cravaro V, Ioannidis JPA, Reichenberg A, Phiphopthatsanee N, Amir T, et al. What causes psychosis? An umbrella review of risk and protective factors. World Psychiatry 2018; 17(1): 49-66.

3 Lund C, De Silva M, Plagerson S, Cooper S, Chisholm D, Das J, et al. Poverty and mental disorders: breaking the cycle in low-income and middle-income countries. Lancet (London, England) 2011; 378(9801): 1502-14.

4 Demyttenaere K, Bruffaerts R, Posada-Villa J, Gasquet I, Kovess V, Lepine JP, et al. Prevalence, severity, and unmet need for treatment of mental disorders in the World Health Organization World Mental Health Surveys. JAMA 2004; 291(21): 2581-90

5 McGorry PD, Edwards J. The feasibility and effectiveness of early intervention in psychotic disorders: the Australian experience. Int Clin Psychopharmacol 1998; 13(suppl 1): S47-52.

6 Correll CU, Galling B, Pawar A, Krivko A, Bonetto C, Ruggeri M, et al. Comparison of early intervention services vs treatment as usual for early-phase psychosis: a systematic review, meta-analysis, and meta-regression. JAMA Psychiatry 2018; 75(6): 555-65

7 Csillag C, Nordentoft M, Mizuno M, Jones PB, Killackey E, Taylor M, et al. Early intervention services in psychosis: from evidence to wide implementation. Early Interv Psychiatry 2016; 10(6): 540-6.

8 Brietzke E, Araripe Neto AG, Dias A, Mansur RB, Bressan RA. Early intervention in psychosis: a map of clinical and research initiatives in Latin America. Rev Bras Psiquiatr 2011; 33(suppl 2): s213-24.

9 Rangaswamy T, Mangala R, Mohan G, Josep J, John S. Early intervention for firstepisode psychosis in India. East Asian Arch Psychiatry 2012; 22(3): 94-9.

10 Bertolote J, McGorry P. Early intervention and recovery for young people with early psychosis: consensus statement. Br J Psychiatry 2005; 187(48): s116-9.

11 Mihalopoulos C, McGorry P, Carter R. Is phase-specific, community-oriented treatment of early psychosis an economically viable method of improving outcome? Acta Psychiatr Scand 1999; 100(1): 47-55.

12 Amos A. Assessing the cost of early intervention in psychosis: a systematic review. Aust N Z J Psychiatry 2012; 46(8): 719-34.

13 Drummond MF, Sculpher MJ, Claxton K, Stoddart GL, Torrance GW. Methods for the Economic Evaluation of Health Care Programmes. Oxford University Press, 2015.

14 Fenwick E, Byford S. A guide to cost-effectiveness acceptability curves. Br J Psychiatry 2005; 187(2): 106.

15 Moher D, Liberati A, Tetzlaff J, Altman DG, The PG. Preferred reporting items for systematic reviews and meta-analyses: the PRISMA statement. PLOS Med 2009; 6(7): e1000097.

16 Evers S, Goossens M, de Vet $H$, van Tulder M, Ament A. Criteria list for assessment of methodological quality of economic evaluations: consensus on Health Economic Criteria. Int J Technol Assess Health Care 2005; 21(2): 240-5.

17 Higgins J, Green S, Collaboration C. Cochrane Handbook for Systematic Reviews of Interventions. Wiley-Blackwell, 2008.

18 Jaime Caro J, Eddy DM, Kan H, Kaltz C, Patel B, Eldessouki R, et al. Questionnaire to assess relevance and credibility of modeling studies for informing health care decision making: an ISPOR-AMCP-NPC Good Practice Task Force report. Value Health 2014; 17(2): 174-82.

19 Anderson R. Systematic reviews of economic evaluations: utility or futility? Health Econ 2010; 19(3): 350-64.

20 Fusar-Poli P. The Clinical High-Risk State for Psychosis (CHR-P), Version II. Schizophr Bull 2017; 43(1): 44-7.

21 Tsiachristas A, Thomas T, Leal J, Lennox BR. Economic impact of early intervention in psychosis services: results from a longitudinal retrospective controlled study in England. BMJ Open 2016; 6(10): e012611.

22 Hastrup $L H$, Kronborg $C$, Bertelsen $M$, Jeppesen $P$, Jorgensen $P$, Petersen $L$, et al. Cost-effectiveness of early intervention in first-episode psychosis: economic evaluation of a randomised controlled trial (the OPUS study). $\mathrm{Br} \mathrm{J}$ Psychiatry 2013; 202(1): 35-41.

23 Perez J, Jin H, Russo DA, Stochl J, Painter M, Shelley G, et al. Clinical effectiveness and cost-effectiveness of tailored intensive liaison between primary and secondary care to identify individuals at risk of a first psychotic illness (the LEGs study): a cluster-randomised controlled trial. Lancet Psychiatry 2015; 2(11): 984-93.

24 Mccrone P, Craig TK, Power P, Garety PA. Cost-effectiveness of an early intervention service for people with psychosis. Br J Psychiatry 2010; 196(5): 377-82.

25 Zhang Z, Zhai J, Wei Q, Qi J, Guo X, Zhao J. Cost-effectiveness analysis of psychosocial intervention for early stage schizophrenia in China: a randomized, one-year study. BMC Psychiatry 2014; 14: 212. 
26 Rosenheck R, Leslie D, Sint K, Lin H, Robinson DG, Schooler NR, et al. Costeffectiveness of comprehensive, integrated care for first episode psychosis in the NIMH RAISE early treatment program. Schizophr Bull 2016; 42(4): 896-906.

27 Cocchi A, Mapelli V, Meneghelli A, Preti A. Cost-effectiveness of treating firstepisode psychosis: five-year follow-up results from an Italian early intervention programme. Early Interv Psychiatry 2011; 5(3): 203-11.

28 Cullberg J, Mattsson M, Levander S, Holmqvist R, Tomsmark L, Elingfors C, et al. Treatment costs and clinical outcome for first episode schizophrenia patients: a 3-year follow-up of the Swedish 'Parachute Project' and two comparison groups. Acta Psychiatr Scand 2006; 114(4): 274-81.

29 Goldberg K, Norman R, Hoch J, Schmitz N, Windell D, Brown N, et al. Impact of a specialized early intervention service for psychotic disorders on patient characteristics, service use, and hospital costs in a defined catchment area. Can J Psychiatry 2006; 51(14): 895-903.

30 Mihalopoulos C, Harris M, Henry L, Harrigan S, McGorry P. Is early intervention in psychosis cost-effective over the long term? Schizophr Bull 2009; 35(5): 909-18.

31 Behan C, Cullinan J, Kennelly B, Turner N, Owens E, Lau A, et al. Estimating the cost and effect of early intervention on in-patient admission in first episode psychosis. J Ment Health Policy Econ 2015; 18(2): 57-62.

32 Park AL, McCrone $\mathrm{P}$, Knapp M. Early intervention for first-episode psychosis: broadening the scope of economic estimates. Early Interv Psychiatry 2016; 10(2): 144-51.

33 McCrone $\mathrm{P}$, Knapp M, Dhanasiri S. Economic impact of services for firstepisode psychosis: a decision model approach. Early Interv Psychiatry 2009; 3(4): 266-73

34 Wong KK, Chan SKW, Lam MML, Hui CLM, Hung SF, Tay M, et al. Cost-effectiveness of an early assessment service for young people with early psychosis in Hong Kong. Aust N Z J Psychiatry 2011; 45(8): 673-80.

35 Ising H, Smit F, Veling W, Rietdijk J, Dragt S, Klaassen R, et al. Cost-effectiveness of preventing first-episode psychosis in ultra-high-risk subjects: multi-centre randomized controlled trial. Psychol Med 2015; 45(7): 1435-46.

36 Ising HK, Lokkerbol J, Rietdijk J, Dragt S, Klaassen RM, Kraan T, et al. Four-year cost-effectiveness of cognitive behavior therapy for preventing first-episode psychosis: the Dutch Early Detection Intervention Evaluation (EDIE-NL) trial. Schizophr Bull 2017; 43(2): 365-74.

37 Phillips LJ, Cotton S, Mihalopoulos C, Shih S, Yung AR, Carter R, et al. Cost implications of specific and non-specific treatment for young persons at ultra high risk of developing a first episode of psychosis. Early Interv Psychiatry 2009; 3(1): 28-34.

38 Chong HY, Teoh SL, Wu DB, Kotirum S, Chiou CF, Chaiyakunapruk N. Global economic burden of schizophrenia: a systematic review. Neuropsychiatr Dis Treat 2016; 12: 357-73.

39 Ioannidis JP. Why most published research findings are false. PLOS Med 2005: 2(8): e124

40 Pelosi AJ, Birchwood M. Is early intervention for psychosis a waste of valuable resources? Br J Psychiatry 2003; 182: 196-8.

41 Farooq $\mathrm{S}$. Early intervention for psychosis in low- and middle-income countries needs a public health approach. Br J Psychiatry 2013; 202(3): 168-9. 